Artículo

\title{
Crítica, economía, dietética. Derrida, Benjamin y Viveiros de Castro sobre la violencia
}

\author{
Critique, Economy, Dietetics. Derrida, Benjamin and Viveiros de Castro on Violence
}

\author{
Valeria Campos Salvaterra* \\ *Pontificia Universidad Católica de Valparaíso
}

\section{Resumen:}

Mediante un hilo tejido a través de la filosofía de Jacques Derrida, en diálogo con Walter Benjamin y Eduardo Viveiros de Castro, este trabajo traza un recorrido deconstructivo respecto de la relación entre violencia y representación. Sostenemos que un paradigma crítico, como el que performa el texto de Benjamin de 1921 sobre la violencia, no puede desestabilizar por completo la ley fenomenológica que emparenta la representación con la violencia. A partir de las propuestas de Derrida sobre una archi-violencia o violencia originaria, mostramos la necesidad del paso a un paradigma económico, que no reproduce los gestos de corte y clasificación de la crítica benjaminiana. Todo esto es bien conocido dados los escritos de Derrida sobre Benjamin. Damos un paso más allá al asociar esta economía de la violencia a una cierta lógica dietética: a partir de la forma caníbal del comerse al otro (manger l'autre), bien articulada por Viveiros de Castro en relación con los cánones epistemológicos del pensamiento europeo en relación con el "nuevo mundo". A partir de seminarios inéditos de Derrida, mostramos la posibilidad de abordar la relación entre violencia y representación desde un cierto "canibalismo especulativo" de nuevo cuño.

Palabras clave: Derrida; Benjamin; Viveiros de Castro; Violencia; Representación; Canibalismo.

\section{Abstract:}


Through the philosophy of Jacques Derrida, in dialogue with Walter Benjamin and Eduardo Viveiros de Castro, this work traces a deconstructive path regarding the relationship between violence and representation. We argue that a critical paradigm, such as the one performed by Benjamin's 1921 text on violence, cannot completely destabilize the phenomenological law that links representation to violence. Starting from Derrida's proposals on arche-violence or original violence, we show the need to move forward to an economic paradigm, which does not reproduce the cutting and classification gestures of Benjaminian criticism. All of this is well known given Derrida's writings on Benjamin. We go a step further by associating this economy of violence to a certain dietetic logic: from the cannibalistic dynamic of eating the other (manger l'autre), well articulated by Viveiros de Castro in relation to the epistemological canons of European thought in relation to the "new world". Based on unpublished seminars given by Derrida, we show the possibility of approaching the relationship between violence and representation from a certain "speculative cannibalism" of a new kind.

Keywords: Derrida; Benjamin; Viveiros de Castro; Violence; Representation; Cannibalism.

Recibido: 13 de abril de 2020

Aceptado: 15 de junio de 2020

Me interesa tan sólo elucidar qué era eso que los jesuitas y demás observadores llamaban la 'inconstancia' de los Tupinambá. Se trata sin duda de una cosa bien real, incluso si se le quiere dar otro nombre; si no un modo de ser, era un modo de aparecer de la sociedad Tupinambá ante los ojos de los misioneros. Es preciso situarlo en el cuadro más amplio de la bulimia ideológica de los indios, de aquél intenso interés con que escuchaban y asimilaban el mensaje cristiano sobre Dios, el alma y el mundo. Pues, es necesario repetirlo, lo que exasperaba

a los padres no era ninguna resistencia activa que los 'brasis' ofreciesen al Evangelio en nombre de otras creencias, sino el hecho de que su relación con la 
creencia era intrigante: dispuestos a todo engullir, cuando se los tenía por ganados, ellos recalcitraban volviendo al "vómito de las antiguas costumbres" José de Anchieta 1555: II, $194^{1}$

La "inconstancia del alma salvaje" es la tesis con la que Eduardo Viveiros de Castro quisiera mostrar el modo en que los colonos europeos describieron el carácter de los indios americanos, especialmente refiriendo a la tribu de los Tupinambá en lo que es el Brasil actual $^{2}$. En el presente trabajo mostramos, a través de cuatro breves momentos, cómo esta inconstancia no es ni un predicado esencial ni exclusivo del "alma" salvaje -propio, según las connotaciones del $\ddot{i} \delta$ lov griego $^{3}$-, pero tampoco meramente accidental; sino que, extendiéndolo más allá de estos límites, decimos que es el predicado general de toda predicación y, así, de toda configuración significativa del mundo. De toda re-presentación o aparición del mismo, o de toda "alma", si se quiere ${ }^{4}$. Inconstancia que los europeos calificaron sin duda de violenta, y ante la cual respondieron con todo el peso y la fuerza de la "constancia". Se trata entonces de una violencia de contragolpe contra una violencia primera, "originaria", "salvaje”, que constituye la inconstancia a partir de una lógica siguiendo a Viveiros de Castro- de apertura que "es la expresión de un modo de ser donde es el intercambio y no la identidad, el valor fundamental a ser afirmado"

\footnotetext{
${ }^{1}$ Citado por Eduardo Viveiros de Castro, "O mármore e a murta: sobre a inconstância da alma selvagem", en $A$ inconstância da alma selvagem e outros ensaios de antropología (Sao Paulo: Cosac Naify, 2002), 190. En adelante, todas las traducciones son de nuestra autoría, a no ser que se indique lo contrario.

${ }^{2}$ Viveiros de Castro, "O mármore e a murta".

${ }^{3}$ La palabra griega $\ddot{\delta} \delta$ lov designa lo propio. Lo propio, según el sentido que le da Aristóteles -entre otros lugares, en su Ética nicómacomáquea (Madrid: Editorial Gredos, 1995),1097b, en referencia a la función propia del alma humana- es lo que se predica "en sentido estricto", en sentido estrecho, estrechamente, únicamente, exclusivamente. Estas características en Aristóteles también designan lo propio en cuanto uno

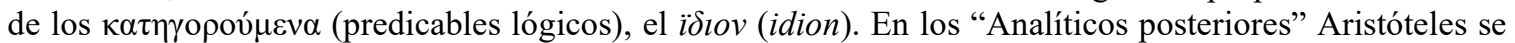
refiere a cinco predicables, o modos generales de atribución: género, especie, diferencia, propio y accidente. El género representa la parte de la esencia que es común a varias especies; la especie representa la esencia del ser; la diferencia expresa la parte de la esencia que no es común, sino característica de la especie; propio, o propiedad, expresa una cualidad que acompaña necesariamente a la especie, y el accidente expresa una cualidad contingente, que puede estar o no en el ser. Ver Aristóteles, "Analíticos posteriores", en Organon II. Miguel Candel Sanmartín trad. (Madrid: Gredos, 1995), 73a7; 76a38; 91a15; 92a8. Una consideración similar en "Tópicos", en Organon I. Miguel Candel Sanmartín trad. (Madrid: Editoral Gredos, 1982), 15.

${ }^{4}$ La conversión entre el aparecer y el alma puede sostenerse a partir de la clásica idea aristotélica de que "el alma es en cierto sentido todas las cosas". Aristóteles, Acerca el alma, Miguel Candel Sanmartín trad. (Madrid: Editorial Gredos, 2014), 431b 21. Cuestión que, es sabido, es enfáticamente recibida por Heidegger en la propedéutica de la analítica existencial de Ser y tiempo. Ver Martin Heidegger, Ser y tiempo, Jorge Eduardo Rivera trad. (Santiago: Editorial Universitaria, 1997), 37.

${ }^{5}$ Viveiros de Castro, "O mármore e a murta...", 206. Cursivas nuestras.
} 
A través de un cruce de los análisis que Walter Benjamin, Jacques Derrida y Viveiros de Castro hacen de la cuestión de la violencia, articulamos una propuesta de lectura que apunta específicamente a su relación con la representación. En un primer momento, abordamos el vínculo entre violencia y representación a partir de la crítica benjaminiana de $1921^{6}$. Posteriormente, nos volcamos hacia la idea de una "violencia originaria" o "archi-violencia", trabajada por Jacques Derrida en sus escritos tempranos ${ }^{7}$ para, por un lado, mostrar el punto ciego de la crítica y, por otro, engarzar dicha tesis con la posibilidad de sostener una economía de la violencia: una aproximación deconstructiva cuya dinámica económica no está, sin embargo, restringida a las normas tradicionales -y fundacionales- del oikos. Por último, proponemos un paso más allá, hacia una apuesta ético-política que enfrente la relación violencia-representación desde un nuevo ángulo: una suerte de canibalismo especulativo que, entre el de Viveiros de Castro y el de Derrida, nos permite sostener que en el paso a lo común -a lo general y lo público- propio de toda operación representativa, el cum de la comunidad es siempre un comer-con-otro. En otras palabras: una dietética.

\section{Primer momento: la crítica}

Antes de dejar el campo de batalla, despedazaban a los muertos y sus miembros asados eran o bien comidos en el lugar, o bien llevados a la aldea. Los Tupinambá cortaban también los órganos genitales de las mujeres y los niños muertos durante el combate y se los entregaban a sus mujeres, que los ahumaban

y se los servían en trozos en grandes ocasiones

Alfred Métraux, Antropofagia y cultura

¿Puede una crítica de la representación ser a la vez una crítica de la violencia? ¿Puede la representación leerse en términos de violencia? Estas son las preguntas con la que se comienza a articular nuestra propuesta. Si las respuestas a ellas fuesen afirmativas, otra pregunta se seguiría: ¿cómo? ¿Cómo hablar de la representación como forma de violencia?

\footnotetext{
${ }^{6}$ Usamos la siguiente edición castellana: Walter Benjamin, "Para una crítica de la violencia", Pablo Oyarzún trad., en Letal e incruenta. Walter Benjamin y la crítica de la violencia (Santiago: Lom ediciones, 2017).

${ }^{7}$ Explícitamente, ver Jacques Derrida, "Violence et métaphysique. Essai sur la pensée d'Emmanuel Levinas", en La ecriture et la différence (París: Galilée, 1967), y De la grammatologie (París: Galilée, 1967).
} 
El texto de Walter Benjamin Para una crítica de la violencia es en este sentido analíticamente muy útil, al circunscribir la cuestión de la violencia al ámbito del derecho y de la justicia o, como él lo llama, al terreno de las relaciones éticas (Sittliche). Esto podría tomarse como base para relacionar violencia y representación, y podría hacerse de al menos dos maneras que son, en todo caso, solidarias:

1) En cuanto toda representación se rige por ciertas leyes, ciertas normatividades que condicionan sus posibilidades formalizadoras de la experiencia, que podríamos llamar en términos amplios leyes de la idealización o virtualización del sentido, y que son en principio las que sostienen la clásica diferenciación entre una dimensión de facto y una de jure; es decir, la distinción entre lo que podíamos señalar históricamente en la filosofía occidental como el terreno de los "hechos", de la "realidad efectiva" (Wirklichkeit), versus el terreno de lo que el idealismo -sobre todo la fenomenología- llama "sentido" y lo opone al primero. Estas oposiciones, tan presentes en la filosofía -de Platón a Husserl-, están montadas sobre una normatividad propia de los textos filosóficos de la que podríamos, sin duda, sacar conclusiones ético-políticas y ponerlas en relación con una idea de violencia.

2) Aun más interesante, en cuanto como dice Derrida toda ley es de estructura fenomenológica, pues su esquema de fundamentación es tautológicamente performativo: la ley -cito a Derrida- "se pone a ella misma violentamente decretando que es violento todo aquello que no la reconoce" "9; esto quiere decir que la ley se pone performativamente a sí misma y a todas las convenciones que justifican su violencia retrospectivamente. ¿Pero, por qué esto refiere a una estructura fenomenológica? Porque la fenomenología actúa de manera análoga a la ley al instituir su propio principio de los principios, a saber: a falta de origen del sentido, la fenomenología responde poniéndolo performativamente,

\footnotetext{
${ }^{8}$ Tema de la metafísica moderna, especialmente renovado por Kant respecto de Wolff y Baumgärten, se reconfigura en Hegel y es sostenida consistenemente por Husserl a partir de la distinción latina de facto /de jure. Los análisis de Derrida sobre Husserl, sobre todo en su Introducción a El origen de la geometría, están especialmente articulados en torno a esta distinción. Ver Jacques Derrida, Introduction a L'origine de la géometrie de Husserl (París: PUF, 1962). También nuestro estudio sobre el tema en Valeria Campos, Violencia y fenomenología. Derrida entre Husserl y Levinas (Santiago: Editorial Metales Pesados, 2017). Sobre la génesis de la distinción en el idealismo alemán entre Realität y Wirklichkeit véase Jean-Louise Vieillard-Baron, "La 'Wirklichkeit' ou réalité effective dans les 'Principes de la philosophie du droit' de Hegel", Revue Philosophique de Louvain 103, no. 3 (2005): 347-63.

9 Jacques Derrida, "Prénom de Benjamin", en Force de loi. Le 'fondament mystiquet' de l'autorité (París: Galilée, 1994), 83.
} 
escondiendo su violencia tajante tras una investigación retrospectiva de ese mismo origen que, por necesidad, debe ser crítica de todo aquello que amenaza su estatuto de principio ${ }^{10}$.

En ambos casos, pero sobre todo en el segundo, violencia y representación estarían unidas por ese término medio que es la estructura de la ley, que en la forma de una retórica jurídica -presente justamente en clásica distinción entre de facto y de jure-, ha condicionado históricamente los modos de aparición del mundo. Habría ahora que preguntar por la posibilidad de que dicha ley estuviera, a su vez, condicionada de vuelta por los modos de aparición que hace posibles, cuestión que depende de que no sean determinables hasta el límite. Se trata del ya viejo problema de la historicidad del sentido, abierto en la modernidad explícitamente por Hegel, asumido tardíamente por la fenomenología husserliana y desarrollado extensivamente por Heidegger. Derrida se ha hecho cargo de la historia y configuraciones de este problema en relación con estos tres autores $^{11}$, y sobre sus tesis basaremos las conclusiones que siguen en este trabajo. Si es posible dicha relación doble entre violencia y representación, entonces no solo es posible identificar una cierta violencia asociada a la representación, sino que también sería posible, en consecuencia, su crítica.

Derrida muestra primero en relación con Emmanuel Levinas ${ }^{12}$ que dicha crítica de la violencia no puede tomar una posición absolutamente exterior respecto de la representación misma; o, lo que es lo mismo, una posición exterior al derecho. Pues si dicha crítica no es puramente destructiva, como en el caso de Levinas, el hecho de la singularidad concreta del Otro deviene inevitablemente, otra vez, un derecho ${ }^{13}$. Estos

\footnotetext{
${ }^{10}$ La tesis de Derrida sobre esta operación señala que la ley se pone a sí misma escondiendo ese momento performativo, sintetizando el tiempo de modo que parezca ya constituido de antemano, a priori. El origen se pone en forma de investigación retrospectiva o cuestionamiento retrospectivo, Rükfrage, de modo que la violencia de su posición se desplaza y, así, se esconde tras y acusa a todo aquello que podría negar el estatuto de principio del origen que pone: la crisis, el olvido. Jacques Derrida, Introduction a l'Origine de la gémoetrie, y Le problème de genèse dans la philosophie de Husserl (París: PUF, 1990), 2.

${ }^{11}$ Respecto de Hegel, cf. sobre todo Jacques Derrida, Glas (París: Galilée, 1974). Sin embargo, son quizás más directos los análisis que vía Heidegger hace Derrida de este problema en Heidegger: la question de l'Être et l'Histoire. Cours de L'ENS-Ulm 1964-1965 (París: Galilée, 2013). Para Husserl, lo encontramos sobre todo en Introduction a l'Origine de la gémoetrie.

${ }^{12}$ En el citado ensayo de 1964 "Violence et métaphysique", publicado en La ecriture et la différence.

${ }^{13}$ Dice Derrida: "Retornar, como al único punto de partida posible, al fenómeno intencional en el que el otro aparece como otro y se presta al lenguaje, a todo lenguaje posible, es quizás entregarse a la violencia, hacerse cómplice al menos de ella y dar derecho -en el sentido crítico-a la violencia del hecho. Pero se trata entonces de una zona irreductible de la facticidad, de una violencia originaria, trascendental, anterior a toda elección ética, supuesta, incluso, por la no-violencia ética". Derrida, Violence et métaphysique, 183-4. Terceras cursivas nuestras.
} 
análisis llevan a Derrida -en una primera etapa de su lectura de Levinas- a considerar que su operación de absolutización del infinito del otro reproduzca la misma situación que el pensador lituano quiere criticar bajo el concepto de "totalidad"14. El resultado se plasma en una relación que Derrida establece entre el silencio y lo peor: dejar al otro fuera de la representación para evitar la violencia de esta última sería, entonces, también una situación de violencia, pero más peligrosa: solapada, silenciosa, que excluye lo singular del espacio público $^{15}$. Derrida muestra luego que dicha crítica de la violencia, que la tiene como su blanco, podría provenir de la violencia también, como lo señala Benjamin. De este modo, no podría hallarse en la configuración de lo jurídico en general, ni más allá de este, ningún área libre de violencia. La violencia estaría por todos lados. La crítica de Benjamin implicaría, sin embargo, la posibilidad de diferenciar y distinguir entre violencias, de establecer cortes entre diversos tipos -o trozos- de violencia, que no se mezclan, que se mantienen separadas y que son unas más violentas que otras, es decir: unas más cruentas, más despóticas, más execrables, más bastardas que otras ${ }^{16}$. Siguiendo a Benjamin, solo una filosofia de la historia ${ }^{17}$ que pueda distinguir entre el ciclo mítico y estático de las violencias del derecho y la posibilidad de otro tiempo histórico podría llevarla a cabo. Pero esa filosofía de la historia no se configura, ciertamente, sin violencia.

\footnotetext{
${ }^{14}$ Esta lectura de Derrida está correctamente fundada en la descripción misma de totalidad con la que trabaja Emmanuel Levinas en su texto Totalité et infini. Essai sur l'extériorité (Dordrecht: Kluwer Academic Publishers, 1988). [Edicion en castellano: Totalidad e infinito. Ensayo sobre la exterioridad. Daniel E. Guillot trad. (Salamanca, Editorial Sígueme, 2002)]. En cuanto estructura finita que opera como principio de inteligibilidad, la totalidad se encuentra comandada por la regla de reducción de la alteridad a la conciencia en el seno de la experiencia. Cf. Patricio Peñalver, Argumento de alteridad (Madrid: Editorial Caparrós, 2000), 173. Sin embargo, hemos mostrado en otro trabajo que si bien la violencia en Levinas está en relación con la crítica a la filosofía de la totalización, no puede reducirse a ella. Mientras el concepto de totalidad refiere al ejercicio del poder y la dominación, la cuestión de la violencia remite a una situación extrema, que Levinas vincula con el asesinato en cuanto solución final. Esto supone sostener la impotencia de la totalización frente a la absoluta alteridad del otro hombre, lo que permite pensar la relación mismo-otro bajo una nueva y paradójica lógica jurídica. Cf. Valeria Campos, "Asesinar al otro. Ética, violencia y poder en la filosofía de Emmanuel Lévinas", Hybris Revista de Filosofia 10, no. 1 (2019).

${ }^{15}$ Se trata de lo que Derrida describe como violencia del silencio absoluto, primitivo y pre-lógico, Cf. Derrida, "Violence et mátaphysique", 172-3. O, en términos husserlianos, la violencia de una singularidad "salvaje", la violencia del apeiron que acecha cada vez que se quiere despojar al "hecho" de su función fenomenológica. Cf. Derrida, Introduction a l'Origine de la géometrie, 169.

${ }^{16}$ Las distinciones que Benjamin establece ente violencia mítica y divina, hacen de la primera impura, excecrable y derramadora de sangre, injusta, bastarda, vs la segunda que sería pura, letal pero incruenta, justa. Cf. Benjamin, Para una crítica de la violencia.

${ }^{17}$ Dice Benjamin: "La crítica de la violencia es la filosofía de su historia. «Filosofía» de esta historia, porque sólo la idea de su punto de partida posibilita una postura crítica, discernidora y decisiva con respecto a sus datos cronológicos". Ibíd., 39.
} 


\section{Segundo momento: la violencia originaria}

[El indio] Dice que quiere ser cristiano y no comer carne humana, ni tener más de una mujer y otras cosas; solamente que ha de ir a la guerra y los que ha de tomar cautivos venderlos y servirse de ellos, porque estos de esta tierra siempre tienen guerra con otros y así andan todos en discordia. Se comen unos a otros,

digo a los contrarios.

Viveiros de Castro, "O mármore e a murta"

Sin embargo, Derrida se distancia de Benjamin y toma otros caminos, que consisten en mostrar cómo incluso dicha crítica de la violencia -en el doble sentido genitivo y posesivono puede ser totalmente destructiva. Ella es, como toda crítica, también determinante: juzga en sentido amplio y kantiano, es decir: construye, incluso performa. Y lo hace justamente trozando, des-pedazando para así diferenciar, determinar y asimilar significativamente categorías más o menos puras de violencias. Esa crítica no podría, como en el caso de Levinas, salir de la esfera misma de esa metafórica del derecho que pretende destruir. El caso de Para una crítica de la violencia se inserta en esta lógica en la medida en que, como afirma Derrida, es "una crítica de la representación como perversión y caída del lenguaje" 18 . Si se trata para Benjamin de determinar la violencia de la representación como una caída o como una perversión, es porque el gesto de corte, de distinción, de delimitación también actúa como Ur-tail, como corte originario o juicio que establece en el mismo procedimiento una diferencia jerárquica. El krinein de la crítica no sólo señala su capacidad de poner en cuestión la historia del mito, sino también de elegir, decidir, cortar; tomar respecto del tiempo presente, una posición diferenciadora, decisoria y decisiva ${ }^{19}$. Como hemos ya mostrado en otro texto ${ }^{20}$, estableciendo Benjamin esta posibilidad del corte o de la decisión sobre la base de un suelo indecidible -la violencia divina-, chocaría con una aporía que lo emparenta inevitablemente con Heidegger $^{21}$ : la aporía que emerge cuando, a

\footnotetext{
${ }^{18}$ Derrida, Prénom de Benjamin, 69. Cursivas nuestras.

${ }^{19}$ Ibid., 128

${ }^{20}$ Valeria Campos, "El gran criminal. Violencia, ley y soberanía”, en Transacciones peligrosas. Economías de la violencia en Jacques Derrida (Santiago: Ediciones Pólvora, 2018).

${ }^{21}$ Benjamin, y en especial su nombre de pila, tendrían para Derrida su lugar -lugar diferido, incierto, por tanto- en la línea genealógica que Derrida en otro lugar llamó la psyché judeo-alemana: "la lógica de ciertos
} 
partir de lo que solo se da (est gib), se establece todo un sistema de derivaciones, de niveles "originarios" respecto de otros "vulgares"22.

La propuesta de Derrida, entonces, se establece como una bifurcación respecto de la de Benjamin. Manteniendo la idea de que la crítica proviene de y se realiza sobre la violencia, habría que llegar a los conceptos de violencia originaria, archi-violencia y violencia trascendental, configurados por Derrida ${ }^{23}$, pero que nunca dejan de acompañar el paso y ritmo de su filosofía. Hemos propuesto que dichos conceptos tienen su génesis ya en la lectura que Derrida hace de Husserl y del autodiferimiento que se produce en el movimiento de autoafección como condición de posibilidad del sentido, siempre en relación con la alteridad en general: ella se encuentra, en primer lugar, en los análisis que hace Derrida de la temporalización, posteriormente en relación con los argumentos sobre la presentación de la alteridad y su constitución por analogía, para tener su punto más álgido respecto de la tesis de la voz fenomenológica ${ }^{24}$. Cuestiones que Derrida resumirá en 1990,

fenómenos de turbadora especularidad, reflejada ésta a su vez en ciertas grandes figuras de pensadores y escritores judíos alemanes de este siglo, Cohen, Buber, Rosenweig, Scholem, Adorno, Arendt y, justamente, Benjamin”. Derrida, Prénom de Benjamin, 72; también Kant, el judio, el alemán. Patricio Peñalver trad. (Madrid: Editorial Trotta, 2004). Benjamin queda así de entrada inscrito a su vez en una cierta línea de herencia cuyas articulaciones, sin embargo -como en toda linea- se mantienen siempre secretas. En esta herencia, el judaísmo entraría en una cierta alianza con el idealismo, e incluso "se confundiría con el platonismo" (Derrida, Kant, el judío, el alemán, 83), dice Derrida, lo que lo emparentaría también con el protestantismo alemán que está en los orígenes de una cierta "modernidad". Y éste, a su vez, sobre todo a través de Kant, vincularía a Benjamin también con un cierto Heidegger. Pero la articulación parece estar dada también por la sugerida reflexión sobre la "solución final" del nazismo que Derrida querría llevar a cabo en el texto del 90, justamente a partir de la constatación de Benjamin de la indecidibilidad de la violencia divina para los humanos en conexión con su manifestación en la violencia revolucionaria. Pues si el índice de la manifestación de la violencia divina en el terreno de la acción humana incluye que esta sea un momento de "realización incruenta, contundente, redentora", no sería muy descabellado asociarla a los campos de exterminio nazi, con sus cámaras de gas que no derramaron ni una gota de sangre (Derrida, Prénom de Benjamin, 145). Independientemente de si estas conclusiones de Derrida son "fieles" o no al texto benjaminiano, lo que sí se muestra en la deconstrucción es esta paradoja según la cual se pretende establecer una cierta soberanía del método, de la crítica, del krinein en general -de los textos filosóficos y sus leyes, por tanto- sobre un fundamento no lo suficientemente soberano, sino más bien débil, como en este caso la indecidibilidad.

${ }^{22}$ Ver Jacques Derrida, "Geschlecht I. Diferencia sexual, diferencia ontológica”, en Psyché. Invenciones del otro, Alejandro Madrid trad. (Buenos Aires: La Cebra ediciones, 2017). A pesar de que Heidegger sostiene que el ser es sexualmente neutro, Derrida mostrará cómo el ejercicio de regresión que realiza Heidegger desde lo diferenciado del ente, en cuanto su sentido es derivado, caído, incluso vulgar, impide pensar lo originario del ser de modo neutro.

${ }^{23}$ En relación con Levinas en "Violence et métaphysisque" y con Lévi-Strauss en De la grammatologie. Hemos postulado en otros trabajos que dicha formulación tiene su antecedente en la lectura que Derrida hace de Husserl, sobre todo en Introduction a l'Oigine de la géometrie y en Le problem de la génese.

${ }^{24}$ Derrida, Introduction a L'Origine de la géometrie; "Violence et métaphysique" y La voix et le phénomène (París: PUF-Quadrige, 2006). 
con motivo de la publicación de su memoria de 1956, mediante la idea de "una coimplicación originaria del origen, una contaminación inicial de lo simple" ${ }^{25}$. La noción de "violencia" se adhiere en relación con las críticas de la violencia que llevan a cabo de modo explícito Levinas y de modo implícito Lévi-Strauss, para reaparecer en relación con Benjamin en el texto que hemos estado citando, Prénom de Benjamin. En los tres casos, Derrida analiza argumentos duramente críticos de los paradigmas epistemológicos de la modernidad, argumentos fundados en la consideración de sus consecuencias éticopolíticas. Derrida muestra los lugares en que dichos textos reproducen solapadamente las lógicas puestas en cuestión, impidiéndoles sostener un privilegio axiológico respecto de un área de no-violencia pura ${ }^{26}$.

Esta tesis sobre una violencia originaria, puesta en relación con la normatividad textual fenomenológica a la que hemos estado refiriendo, muestra que el derecho mismo, su fuerza performativa, su violencia toda está dividida, pero internamente; diferida y diferenciada en el corazón de su autorreferencia y, por tanto, nunca puede alzarse como soberana -si es que la soberanía es, como explica Derrida también por referencia a Benveniste, la estructura misma de la mismidad y la mismidad como estructura ${ }^{27}$ : la ipseidad como movimiento infinitamente autorreferencial de constitución de la identidad como tautología performativa-. Dicha división interna de la ley muestra que su violencia no proviene de ella como su efecto, pues ella misma no puede entenderse en ningún sentido como causa sustancial de la violencia. La ley misma tendría que pensarse como interiormente ya afectada y debilitada por la violencia que ella misma instala, cuya instalación forzada está así también debilitada por una lucha interna irreductible. Débil fuerza de la ley que, esta vez y nuevamente con Benjamin, puede decirse quizás mesiánica ${ }^{28}$. La archi-violencia no proviene del origen, sino que está ella misma en el lugar del origen, supliéndolo, sustituyéndolo, poniendo en el lugar de toda idea de origen simple el double bind polémico

\footnotetext{
${ }^{25}$ Derrida, Le problème de la genèse, Prólogo, vii-viii.

${ }^{26}$ En relación con este tema, véase Valeria Campos, "The Original Polemos. Phenomenology and Violence in Jacques Derrida", The Meanings of Violence. From Critical Theory to Biopolitics, G. Rae, y E. Ingala eds. (Nueva York: Routledge, 2018).

${ }^{27}$ Jacques Derrida, Seminario La bestia y el soberano. Volumen I (2001-2002), Cristina de Peretti y Delmiro Rocha trads. (Buenos Aires: Editorial Manantial, 2011), 92-3.

${ }^{28}$ Walter Benjamin, Tesis de filosofia de la historia, Jesús Aguirre trad. (Madrid: Editorial Taurus, 1973), Tesis 2. Derrida cita este pasaje en Spectres de Marx. L'État de la dette, le travail du deuil et la nouvelle Internationale (París: Galilée, 1993), 95.
} 
y contencioso del más-de-uno ${ }^{29}$, de la coimplicación, no pudiendo haber más origen en sentido estricto. Origen, entonces, como lucha y mezcla de contrarios ${ }^{30}$, como guerra interminable, como discordia constitutiva: como el comerse unos-a-otros de los Tupí a sus enemigos.

\title{
Tercer momento: la economía
}

Para los amerindios no se trataba de imponer maniacamente su identidad sobre el otro, o rechazarlo en nombre de la propia excelencia étnica; pero sí de, actualizando una relación con él (relación desde siempre existente de un modo virtual), transformar la propia identidad.

Viveiros de Castro, "O mármore e a murta"

\begin{abstract}
¿Cómo criticar esa violencia como origen de la experiencia, si toda crítica en cuanto determinante -en el doble sentido de constructiva y destructiva a la vez-implica ya a esa violencia originaria y es producida por ella también? Para responder de alguna manera, tendríamos que ir a ese análisis de los Tristes trópicos de Lévi-Strauss que hace Derrida en De la gramatología, donde se configura una cierta estructura tripartita de la violencia ${ }^{31}$. En
\end{abstract}

\footnotetext{
${ }^{29}$ Según Christopher Johnson, 'The figure of the double bind proliferates, both as a concept and metaphor, across a series of texts from Glas onward'. Ver Cristopher Johnson, System and Writing in the Philosophy of Jacques Derrida (Cambridge: Cambridge University Press, 1993), 130. Sin embargo, sugiero que el concepto ya está configurado en ciernes en Le problem de la genèse como "double mouvement de l'intentionalité" (Derrida, Le problem de la genèse, 152), y en De la grammatologie como 'double rejilla (double grille) histórica y sistemática" (Derrida, De la grammatologie, 145). Sin embargo, donde mejor queda explicada la lógica del double bind en su etapa inicial es en Jacques Derrida, La dissémination (París: Seuil, 1972), 10.

${ }^{30} \mathrm{Y}$ si hemos de referir a Benjamin nuevamente, hablaríamos de esa violencia griega del Centauro que de la judía de la palabra. Para esta distinción véase Federico Rodríguez, "Centaurus. Para una ontología poética de la violencia", en Letal e incruenta. Walter Benjamin y la crítica de la violencia (Santiago: Lom ediciones, 2017), 113.

31 "Habría, en efecto, una primera violencia en el nombrar. Nombrar, dar los nombres que estaría eventualmente prohibido pronunciar, tal es la violencia originaria del lenguaje que consiste en inscribir en una diferencia, en clasificar, en suspender el vocativo absoluto. Pensar lo único en el sistema, inscribirlo en él, tal es el gesto de la archi-escritura: archi-violencia, perdida de lo propio, de la proximidad absoluta, de la presencia a sí, perdida en verdad de lo que jamás tuvo lugar, de una presencia así que no ha sido jamás dada sino soñada y siempre ya redoblada, repetida, incapaz de aparecer de otro modo que en su propia desaparición. A partir de esta archi-violencia, prohibida y por tanto confirmada por una segunda violencia reparadora, protectora, que instituye la "moral", que prescribe la ocultación de la escritura, la borradura y la obliteración del nombre que se dice propio que ya dividía lo propio, una tercera violencia puede eventualmente surgir o no surgir (posibilidad empírica) en lo que llamamos corrientemente el mal, la guerra, la indiscreción, la violación: que consiste en revelar por efracción el nombre que se dice propio, es decir, la violencia originaria que ha despojado a lo propio de su propiedad y de su pureza (propreté). Tercera violencia de reflexión, podríamos decir, que desnuda la no-identidad nativa, la clasificación como desnaturalización
} 
el contexto de otro análisis antropológico, que Viveiros de Castro ciertamente hereda, asimila, incorpora en su propio corpus textual ${ }^{32}$, aparece perfilada una "compleja" estructura de la violencia que, sin embargo, no responde ni a una lógica ni a un esquema derivativo. Es más, es una estructura de tres momentos donde, sin embargo, no hay realmente "momentos", o donde los momentos performan esa inconstancia misma del alma salvaje que describen. Tres momentos inconstantes, entonces. Una primera violencia es llamada "originaria", y es adjudicada al lenguaje, especialmente a la operación del nombrar como clasificación de lo singular o "inscripción en una diferencia" ${ }^{33}$. Derrida también escoge llamarla aquí "archi-violencia", en la medida en que es la violencia tomada como una suerte de condición de posibilidad del nombrar que, en cuanto clasificatorio, opera como estructura de la significación en general. Un segundo nivel puede ser llamado "violencia de la ley" o "violencia moral" y es referido al gesto de la prohibición. Específicamente, en cuanto prohibición de la primera violencia o violencia originaria. Es lo que sucede en la sociedad Nambikwara descrita por Lévi-Strauss, donde está prohibido proferir el nombre propio. Una tercera violencia es llamada "violencia en sentido corriente" o "violencia empírica", y refiere a una suerte de contraviolencia sobre el segundo nivel de violencia; una cierta violencia de transgresión de la ley que siempre puede ser juzgada de "mala" o "peligrosa". Por supuesto, este tercer nivel de violencia, dice Derrida, es el más visible de todos, y es por eso que lo llama "violencia en sentido corriente". Es, en efecto, el único que puede ver Lévi-Strauss, y es por eso que a la vez que declara la bondad originaria de los Nambikwara, señala al extranjero -y a lo que éste trae desde fuera: la escritura- como origen del mal ${ }^{34}$. El segundo nivel, la violencia de la ley, no es vista por

de lo propio, y la identidad como momento abstraído del concepto. En este nivel terciario, el de la conciencia empírica, es que debería sin duda situarse el concepto común de violencia”. Derrida, De la grammatologie, $164-5$.

${ }^{32}$ Véase como ejemplo de esta relación la entrevista que Viveiros de Castro realizó a Lévi-Strauss en 1998, "Lévi-Strauss nos 90 a antropologia de cabeça para baixo", Mana 4, no. 2 (1998).

${ }^{33}$ Esta descripción está tomada de lo que el mismo Lévi-Strauss determina como el gesto propio del nombrar: asignar al otro, al singular, a una clase. Derrida cita al antropólogo: "no se nombra jamás: se clasifica al otro". Derrida, De la grammatologie, $160 \mathrm{n}$.

${ }^{34}$ La deconstrucción que opera sobre el texto de Lévi-Strauss tiene como fin, en términos generales, mostrar la denigración que lleva a cabo el antropólogo respecto de la escritura, asociándola con una violencia que sería no sólo la única, sino además unívoca. Esta violencia estaría definida por una constatación histórica de la que la escritura es la condición general de la explotación del hombre por el hombre (Derrida, De la grammatologie, 173ss.), y estaría marcada, signada y desencadenada, por la llegada del extranjero (Ibíd., 166-7). Estas concepciones serían, para Derrida -quien se tomará muchas páginas en mostrarlo-, señales de 
Lévi-Strauss aún como una forma clara de violencia, pues es la condición de ese orden social que describe, justamente, en términos de no-violencia. Esta es la violencia que es críticamente abordada por Benjamin como un gesto de corte agresivo y violento entre lo legal y lo ilegal, sin ningún otro fundamento que la fuerza ínsita en el corte mismo. Es lo que Derrida describe como la respuesta necesaria ante la falta de origen o fundamento para el sentido de la ley en general, tomando por ello la forma de aquella tautología performativa.

¿Cómo, sin embargo, no ver aquí una estructura como tal: derivativa, estática, crítica, des-pedazadora, en suma? No hay krinein porque lo que hay es economía: una estructura dinámica de trans-formación de fuerzas y flujos que están en constante circulación, interrelación, cambio, sustitución, referencia, capitalización, retorno, etcétera ${ }^{35}$. La economía no tiene ni principio ni fin, así como tampoco es en sentido estricto una estructura: sus momentos son sedimentaciones singularmente instanciadas de un flujo que nunca se detiene, y que así como las constituye las destruye en su mismo paso metamórfico. Su asociación con la violencia es descrita también respecto de Levinas, y aparece cuando Derrida nota que la luz, metáfora con la cual la filosofía refiere a las formas del aparecer en general y que Levinas asocia críticamente a la violencia de la totalización, no puede, sin embargo, enfrentarse sino desde el aparecer y el lenguaje mismo: "La palabra es sin duda la primera derrota de la violencia, pero, paradójicamente, esta no existía antes de la posibilidad de la palabra" 36 . Aquí se esboza la economía. Lo importante para comprenderla es el conflicto: para luchar contra una violencia que se entiende como "luz", es necesaria otra luz; no se puede luchar contra ella desde la total oscuridad. En esta lucha se anuncia la posibilidad de un intercambio sin fin que, frente a la imposibilidad de detener

\footnotetext{
una nostalgia roussoniana operando en el trabajo de Lévi-Strauss, y en última instancia darían cuenta de la homogeneidad con que la violencia es descrita por la tradición filosófica, en estrecha relación con la escritura. ${ }^{35}$ En Donner le temps. La fausse monaïe, Derrida se pregunta: ¿Qué es la economía? (Qu'est-ce que l'économie?). Y su respuesta es: "Entre sus predicados o sus valores semánticos irreductibles, la economía comporta sin duda los valores de ley (nomos) y de casa (oikos, es la casa, la propiedad, la familia, el hogar, el calor interior) Nomos no significa solamente ley en general, sino que también ley de la distribución (nemein), la ley de la partición, la ley como partición (moira), la parte dada o asignada, la participación”. Jacques Derrida, Donner le temps. La fausse monaïe (París: Galilée, 1991), 17-8).

${ }^{36}$ Derrida, "Violence et métaphysique", 172-3. Cursivas nuestras.
} 
la lucha e imponer una violencia por sobre otra (que podría decirse "no-violencia" ${ }^{37}$ ), puede describirse como una economía.

Esta noción de economía con la que Derrida trabaja está en relación con un pensamiento de la historicidad, que entiende la violencia de la relación con el otro como lo que permite salir de los cierres que la misma filosofía de la totalidad ha impuesto a la experiencia ${ }^{38}$. La violencia originaria que la corona es, entonces, lo que impide toda fijación de los momentos, así como también toda derivación programática de sus efectos empíricos. Su a priori no puede ser estrictamente condicionante, es decir, no puede clausurar las posibilidades de sus derivas. Así, la violencia en "sentido corriente" es en realidad un cierto pliegue interno de la economía de la violencia y la contraviolencia, esto es, una violencia esencialmente ligada al movimiento obliterante y mutante de la archiviolencia $^{39}$. La economía de la violencia apuntaría justamente a ese desajuste perpetuo de

\footnotetext{
${ }^{37}$ Para Levinas, en la relación con lo Otro, en el encuentro cara-a-cara, se da también una violencia asociada a la ética. Se trata de "la violencia que consiste para un espíritu en recibir a un ser que le es inadecuado" (Levinas, Totalidad e infinito, 51), la fuerza desgarradora de una irrupción en el tiempo del mismo, lo que posteriormente Levinas describe como alteración del arché de la conciencia. Emmanuel Levinas, De otro modo que ser o más allá de la esencia, Antonio Pintor Ramos trad. (Salamanca: Editorial Sígueme, 1987), 164. "La maravilla de la idea de lo infinito" es lo que "irrumpe como violencia esencial en el acto es la excedencia del ser con respecto al pensamiento que pretende contenerlo" (Levinas, Totalidad e infinito, 53). ${ }^{38}$ Levinas, según Derrida, lo sabe: sabe que la filosofía es "histórica de parte a parte" (historique de part en part) (Derrida, "Violence et métaphysique", 172), pues su crítica apunta tanto a la configuración de la experiencia como totalidad finita como a comprender la experiencia de la infinitud del otro como infinito positivo. En ambos casos, la historia se detiene, y la filosofía traiciona su propio compromiso tanto con la historicidad como con la finitud: con lo Otro, en suma. Pues si se trata de abandonar una filosofía de la totalidad, la justicia y la paz no pueden ser ya fines programables; deben desencadenar en el lenguaje una tendencia infinita, que lo obligue a reconocer y a paracticar "una guerra en sí mismo. Violencia contra violencia. Economía de la violencia" (ibíd., 172)

${ }^{39}$ Catherine Malabou parece señalar, en un momento de esta misma estructura, una cierta diferencia jerárquica que habría entre la archi-violencia y la "violencia en sentido corriente", que cuestionaría la lógica misma de la huella como lo que oblitera todos los sentidos propios, a la vez que lo propio del sentido. Malabou sugiere la posibilidad de que tal división implique a su vez la posibilidad de la reducción de lo que Derrida llama "violencia empírica" a la "violencia trascendental" del primer nivel, es decir, la delimitación estricta de un campo de "verdadera violencia" -trascendental- que dejaría fuera toda violencia derivada -empírica. Ver Catherine Malabou, "Économie de la violence, violence de l'économie. Derrida et Marx", Reveu philosophique 2 (1990): 320; también Derrida, De la grammatologie, 166. Sin embargo, como lo hemos esbozado, se sigue de las múltiples aclaraciones que hace Derrida sobre las nociones de "archi" y de "trascendental" -como siempre sometidas a tachadura- que esto no debe entenderse así. Por lo que sigue en el texto de De la gramatología, se entiende que ese "sentido corriente" es en realidad un cierto pliegue interno de la economía de la violencia y la contra-violencia, esto es, una violencia esencialmente ligada al movimiento obliterante de la archi-violencia y nunca simplemente derivada. Nunca se afirmará de modo directo su calidad de "sentido corriente" versus un "sentido propio", lo que implica que esta no se podría ni derivar, ni reducir. En efecto, es a Lévi-Strauss a quien se apunta como causa de esta división: él es quien que ve a esta violencia del golpe, violencia física o empírica entre las niñitas -"guerra en sentido corriente"no solo como la única violencia, sino también como un accidente sobrevenido desde el exterior a un terreno de inocencia y bondad natural, producido ciertamente por la presencia del extraño, del observador, en lugar
} 
lo propio en sí mismo, a su transformación constante y su diferir constitutivo y constituyente respecto de sí. Eco-nomía: ley del intercambio, de la circulación; pero más fundamentalmente, ley del hogar, del oikos, de lo familiar. Ley del en-lo-de-sí, ley de lo propio. Si hay economía -oikos-nomía- de la violencia, hay una ley de lo propio que es una ley de la violencia.

\section{Cuarto momento: la dietética}

Guerra mortal a los enemigos y hospitalidad entusiasta a los europeos, venganza caníbal y voracidad ideológica expresaban la misma propensión y el mismo deseo: absorber al otro y en este proceso alterarse Viveiros de Castro, "O mármore e a murta"

Esa economía sin punto de partida ni de llegada, comandada por una ley violenta desajustada, autodividida, no-soberana, no-fenomenológica, in-constante ${ }^{40}$ - puede ser

de algo inherente al fenómeno general de la violencia como archi-violencia misma del nombrar. Ver Derrida, De la grammatologie, 166. Derrida pone en cuestión la actitud del etnólogo que sitúa la escena de los nombres propios solo a nivel de violencia empírica, como una violación y una catástrofe que afectarían solo accidentalmente a un estado de paz anterior, no solo como si fuese el único nivel, la única forma de violencia, sino que además como siempre totalmente injusta. Derrida muestra que esa violencia empírica es en realidad interior a la economía de la archi-violencia como violencia en general, porque esta violencia empírica no nombra sino una cierta violencia de transgresión, de transgresión de la ley y de la vigilancia policial. Es una violencia de contra-golpe o, más bien, es la misma violencia originaria desbordando -en su movimiento de suplantación- los límites del texto, del texto de la ley y de la ley del texto, sea esta ley puramente simbólica, sea escrita, empírica, totalmente situada y actual. Toda transgresión a posteriori escenifica la trasgresión $a$ priori de la ley del texto, la ley que solo puede ser obedecida mediante la transgresión anticipada. Además, hay que notar que Derrida llama a esta violencia "empírica" justamente porque puede surgir o no surgir, porque su posibilidad es empírica. Pero esa posibilidad empírica -lo hemos sugerido y seguiremos en elloes estructural, es la estructura misma de la violencia diferancial: archi-violencia invaginada, auto-repliegue de la violencia sobre sí misma que la hace sobreponerse a sí en sí. Este repliegue de lo exterior en lo interior, de lo supuestamente exterior a la violencia al interior de ella, la hace ser creadora $y$ destructora, justa $e$ injusta, fuerte $y$ débil, etc. Es solo en ese double bind de la violencia -signado por el $y$ de un al mismo tiempo, y nunca por una mera contradicción dialéctica- que está en juego la posibilidad empírica de la violencia como estructuralmente contenida en la violencia trascendental o archi-violencia y, por tanto, no puede ser totalmente aislada de esa complicación diferancial. De ahí que tratar esta estructura separando sus niveles, intentando hacer coincidir cada nivel con los movimientos que hemos señalado, supondría establecer ciertos cortes y límites cuya legitimidad podría ser cada vez entredicha, es decir, cada vez deconstruida por una apelación a la misma violencia y a la ley del texto o del relato que dichos límites intentarían contener y reducir. Para profundizar este problema, véase Campos, Transacciones peligrosas.

${ }^{40}$ Siguiendo la idea introducida por Hamlet, "The time is out of joint" y seguida por Derrida en Spectres de Marx, sostemos que la dinámica de la ley que opera como mandato y disyunción a la vez, que vincula y desvincula en el corazón de un mismo instante debe rastrearse en la discusión sobre el tiempo, discusión que lleva a cabo Derrida a lo largo de toda su obra y en todas sus épocas textuales, y que puede resumirse en la 
descrita en términos de una dinámica genético-estructural alimentaria y antropofágica o caníbal. Su lógica es el movimiento del comer-al-otro. Comer al otro que no es simplemente desmembrarlo -diseccionarlo, dividirlo- para destruirlo, sino para incorporarlo y, así, asimilarlo. Sin embargo, la asimilación de los caníbales -como los Tupí- parece nunca ser completa, nunca plenificarse, pues está marcada por dos factores que lo impiden: 1) esa "bulimia ideológica" que no puede consumirlo todo, que siempre produce inevitablemente restos; y 2) esa alteración que el otro que se come produce transformando al que come. "Todas las ancianas que habían devorado esa carne cambiaban de nombre al día siguiente", señala Alfred Métraux respecto de las ceremonias Tupí ${ }^{41}$.

En un seminario aún inédito dictado por Derrida el semestre del 89-90, Comerse al otro (Manger l'autre) $)^{42}$ se explora la posibilidad de que una metáfora alimentaria describa la lógica del discurso filosófico de manera satisfactoria, metáfora que describiría a su vez el movimiento mismo del pensamiento, el acto de la comprensión tomado en su dinámica general. Posibilidad que se deja entrever también en un escrito publicado, específicamente una entrevista del año 1989 -contemporánea del seminario- titulada Il faut bien manger. Le calcul du sujet ${ }^{43}$. Sin embargo, dicho tema no se circunscribe solo a estos explícitos lugares de la obra de Derrida: su génesis textual nos remonta a la década de los setentas, época en la que se pone en juego en los escritos del argelino un cierto esquema especulativo que puede relacionarse tanto con las tempranas tesis sobre la autoafección ${ }^{44}$ como proceso de constitución del sí mismo (ipseidad), como también con la operación de consumación idealizante que está a la base de las grandes teorías sobre el origen del sentido en la

formulación shakespereana que citamos. Ver Jacques Derrida, Spectres de Marx. L'État de la dette, le travail du deuil et la nouvelle Internationale (París: Galilée, 1993), 19-86.

${ }^{41}$ Metreaux, Antropofagia y cultura (Buenos Aires: El Cuenco de Plata editores, 2011), 6.

${ }^{42}$ Se trata de un seminario dictado en Estados Unidos y Francia entre 1989 y 1990: Manger l'autre: Politiques de l'amitié, que se engarza con el del período siguiente (1990-91), Rhétoriques du cannibalisme. Ambos seminarios se encuentran archivados en la colección especial Derrida de la biblioteca de la Universidad de California Irvine (UCI). La citación de este seminario se llevará a cabo señalando, en orden sucesivo, el número de caja en que se encuentra archivado el curso, luego el número de carpeta, luego la fecha completa (día/mes/año) en que fue dictada la clase en cuestión, para finalizar con la página establecida por Derrida dentro de esa clase. El curso Manger l'autre está archivado en la caja $\mathrm{N}^{\circ} 20$, en las carpetas 1 a 4 . El curso Rhétoriques du cannibalisme se encuentra en la misma caja, carpetas 13 a 15.

${ }^{43}$ Jacques Derrida, "Hay que comer bien. El cálculo del sujeto", Confines 17 (2005), traducción de Virginia Gallo y Noelia Billi.

${ }^{44}$ Nos referimos a los escritos de juventud de Derrida, especialmente los dedicados a Husserl (1962 y 1990) y a Heidegger (especialmente el seminario de 1956), pero también en relación con Rousseau en De la grammatologie. 
tradición filosófica occidental. Específicamente, nos referiremos a una trilogía de textos que fueron publicados secuencialmente en 1974, 1975 y 1976: Glas, Economímesis y Fors $^{45}$. Sostenemos que este esquema especulativo tiene su génesis en esta trilogía de textos, que operan enriqueciendo la configuración de una apuesta deconstructiva sobre la relación con la alteridad en general, cuestión que -como señalábamos más arribaconstituye el núcleo del problema epistemológico de la historicidad del sentido. Este problema, que es central en la filosofía de Derrida, toma desde estas articulaciones teóricas una consistencia tal que servirá de base para todo su trabajo deconstructivo posterior, desde las tesis sobre la espectralidad del sentido ${ }^{46}$ hasta la ética del don y la hostipitalidad (hostipitalité) ${ }^{47}$ y la política de la autoinmunidad ${ }^{48}$.

A través de la lectura del idealismo de Kant y Hegel en cruce con el psicoanálisis de cuño freudiano, aparece entonces la cuestión de la incorporación. Abierta como tal para Derrida desde el psicoanálisis, en cuanto describe la dinámica general del trabajo de duelo (travail de deuil $)^{49}$, opera en los textos mencionados como un movimiento de traspaso de fronteras desde un campo señalado como "exterior" a uno "interior". Teniendo en cuenta que el movimiento de la différance como origen no-original o no-simple del sentido no remite tan solo a una diferencia espacial (externa) ni a una temporal (interna), sino a una coimplicación de $\operatorname{ambas}^{50}$, siempre puede sostenerse que, para Derrida, esta sigue el ritmo y la pauta de un movimiento incorporativo. Acto que no puede estar determinado, sin embargo, por lo que podríamos llamar un paradigma asimilativo, pues dicha incorporación nunca transforma plenamente ni lo incorporado en el cuerpo que incorpora ni viceversa. De ahí que, en diálogo con el psicoanálisis, Derrida intente desestabilizar el límite entre

\footnotetext{
${ }^{45}$ Jacques Derrida, Glas (París: Galilée, 1974); "Economimesis”, en Mímesis, des articulations, S. Agacinski, S. Kofman, S y J. Derrida, eds. (París: Aubier, 1975); "Fors", en Cryptonymie: le verbier de l'homme aux loups, N. Abraham, y M. Torok eds. (París: Flammarion, 1976).

${ }^{46}$ Derrida, Spectres de Marx.

${ }^{47}$ Jacques Derrida, "Mot d'accueille", en Adieu à Emmanuel Lévinas (París: Galilé, 1997); y Hostipitalité (1995-1996). Seminario inédito archivado en la Derrida Collection/Critical Theory Collection/ Special Collections and Archives/ UCI Library, California, USA.

${ }^{48}$ Ver Jacques Derrida, Voyous (París: Galilée, 2003).

${ }^{49}$ Se trata de un tema ampliamente tratado por Derrida a lo largo de casi todas sus épocas textuales, pero que tiene su génesis conceptual a partir de la trilogía que señalamos, especialmente situada en Glas y profundizada en Fors. A partir de esta formulación, Derrida pensará todas las formas del trabajo, a la vez que el trabajo como formación de todas las formas. Así queda consignado más de una década después, en la que habla de un "trabajo de duelo que es coextensivo a todo trabajo en general". Derrida, Spectres de Marx, 24.

${ }^{50}$ Jacques Derrida, "La différance", en Marges de la philosóphie (París: Minuit, 1972), 8.
} 
una incorporación asimilativa, llamada técnicamente "introyección", y una incorporación que no llega nunca a reducir al objeto perdido a las estructuras de una subjetividad que se volvería así más amplia ${ }^{51}$.

Interrogado por Jean Luc Nancy en la entrevista de 1989, Derrida instaura ahora explícitamente la posibilidad de un "comer" metonímico como el concepto mismo de experiencia ${ }^{52}$ dado, sin duda, por las anteriores constataciones de la estructura retórica del discurso filosófico, cuyo tropo más "auténtico" no es sino el de la incorporación gustosa, la alimentación. Así, dicho "comer” metonímico describe la operación de la subjetividad, en cuanto aprehensión de lo otro por el pensamiento, mediante la experiencia, simbólica o real, del comer-hablar-interiorizar ${ }^{53}$. Esta operación, dice Derrida, es una lógica de reapropiación de lo exterior al sujeto que instaura una "relación a sí como tal" como estructura de la subjetividad, que "es común tanto al idealismo trascendental como al idealismo especulativo como a la analítica existencial" 54 . Este movimiento puede adecuadamente describirse como una interiorización de la exterioridad, y es al mismo tiempo un fenómeno de afección ${ }^{55}$ que opera como principio de constitución del sí mismo, o de la ipseidad de la identidad subjetiva. Derrida reconoce que esta asimilación del otro es el movimiento fundamental de la comprensión y está vinculada además con una cierta "estructura sacrificial de los discursos", que corresponde a un matar (mise a mort) nocriminal, es decir, orientado a la ingestión, incorporación o introyección de un cadáver ${ }^{56}$. Cuando esta estructura simbólica de la ingesta pretende asimilar ese "cadáver" sacrificial del otro de manera total, sin posibilidad de dejar restos indigestos y sin posibilidad de transformación de sí en el proceso, estaríamos ante la lógica de una autoafección pura, o de una fuerte performatividad tautológica de la ley, cuyos problemas, como decíamos, han sido mostrados por Derrida desde sus textos más tempranos. El deseo de una plena digestión asimilatoria y sin resto ${ }^{57}$, de una perfecta asimilación en cuanto reducción del

\footnotetext{
${ }^{51}$ Este es uno de los problemas tratados en Fors, sobre el que volveremos. Posteriormente, aparecerá en múltiples textos a partir de la idea de un "duelo interminable". Como lugar paradigmático en el que se trata, señalamos Jacques Derrida, Mémoires, pour Paul de Man (París: Galilée, 1988), 29.

52 Derrida, Hay que comer bien, 20.

53 Ibid., 19.

${ }^{54}$ Ibid., 10.

55 Esta referencia corresponde al seminario que Derrida dicta el trimestre de 90-91, Rhétoriques du cannibalisme, 20,13,07/11/90:10-11, archivos 13-14-15 de la caja 20.

56 Derrida, Hay que comer bien, 18.

${ }^{57}$ Cuestión que nunca puede ser realmente lograda. Siguiendo a Farrell Krell, si siempre que se come se come
} 
cadáver del otro al cuerpo del sí mismo que se alimenta, es lo que vincula el logo-centrismo a un carno-centrismo: el dominio de una lógica de la relación de incorporación total, sin resto, de lo otro marcado por la necesidad de su sacrificio.

Sin embargo, dicha posibilidad de pura autoafección, cuya interrupción por la alteridad de una exterioridad fue mostrada por Derrida por primera vez en la necesidad de hacer de la escritura un suplemento necesario del habla ${ }^{58}$, queda también entredicha por la imposibilidad de una total ingestión carnívoro-sacrificial del otro. Todos los elementos aquí involucrados pueden ser descritos bajo la temática del comer carne buena o mala, de la prohibición de comer carne, la abstinencia de comer carne, de la sublimación y la substitución de la carne en una dieta carnívora, y de todas las temáticas que se resumen en la figura de la antropofagia y el canibalismo, dice Derrida en el seminario inédito de 19891990 Manger l'autre ${ }^{59}$. Un tópico que está también contenido en la entrevista con Nancy, a propósito de la posibilidad de la deconstrucción del carno-logo-centrismo: no se trata, dice ahí Derrida, de saber si es "bueno" o está “bien” comer al otro, y a cuál otro, pues "lo comemos de todas maneras y nos dejamos comer por él" ${ }^{\prime 60}$. Se trata más bien, entonces, del cómo comer para comer bien, del il faut bien manger como la normatividad general o

algo otro, entonces no puede haber digestión perfecta: "Todo lo que puedes comer es algo otro -no un otro cualquiera, por supuesto, sino el otro nutritivo; aun así, a la digestión le sigue la excreción, la eliminación de lo que en el otro nutritivo no pudo ser asimilado; por tanto, uno no puede comer todo o incluso al otro designado, al menos no sin dejar un residuo, o lo que los franceses llaman restes. Siempre hay sobras y desperdicios, sin mencionar los inmencionables, eliminados para luego ser purgados con agua o fuego purificador. La pregunta de Derrida: ¿cuál es la estructura y el sistema de los desperdicios, las sobras, los restos?". David Farrell Krell, “All You Can't Eat: Derrida's Course, 'Rhétorique Du Cannibalisme' (19901991)", Research in Phenomenology 3 (2006): 136. Esta cuestión es tratada por Derrida mismo en Glas, la obra de Derrida dedicada a Hegel y Genet, la que está totalmente articulada en torno a la cuestión del restar (rester), como mantenerse, pero también del resto (reste) como lo que sobra o queda de una cierta operación sintética (Derrida, Glas, 253), en cuanto residuo material, empírico, tan indeseable como peligroso, capaz de transformarse en una máquina castradora, máquina materialista (ibíd., 54). La constatación primordial de Derrida en este texto es que el pensamiento del resto no puede ser comprendido por la tradición filosófica que encuentra uno de sus momentos culmines en Hegel (ibid., 7), pues para Hegel el movimiento general de la Aufhebung no puede/debe dejar ningún resto; debe ser, por el contrario "total e infinita" (ibíd., 156).

${ }^{58}$ Esto se explica porque la escritura, tradicionalmente desplazada y condenada a ser un mero representante estático y estéril del habla que se piensa como lenguaje pleno, es utilizada estructuralmente por la filosofía como una metáfora-metonimia de la voz, cuya fuerza explicativa es tal que termina por suplantar, al querer solo suplementar, todas las funciones originalmente atribuidas al habla. Este es el centro de la teoría del suplemento de origen, tratado en De la gramatología especialmente en relación con los textos de Rousseau, y es lo que alza a la escritura y a su función retórica como el gran "peligro" para la filosofía. La escritura como suplemento del habla constituye así un uso metafórico-metonímico que es el único sentido propio posible para ella, tornándose así en tropo primero u originario. Derrida, De la grammatologie, 27 y 22.

${ }^{59}$ Derrida, Manger l'autre, 20,1,08/11/89:3

${ }^{60}$ Derrida, Hay que comer bien, 20. 
incluso la ley de toda relación con el otro; ya sea en cuanto ley de la fenomenalización del otro a partir de la autoafección, ya sea en cuanto ley de la comunión, la comunidad y la hospitalidad, de la acogida del otro. La ética de esta proposición es entonces una dietética: ética de la incorporación sin asimilación posible, estructura tensionada, double bind de lo otro-en-lo-mimo, sustitución del otro por mí como estructura de la subjetividad. Duelo originario, también. Ética como dietética caníbal donde el otro que se come altera al que lo come.

La violencia originaria, esa fuerza que está en el lugar del origen, sustituyéndolo, impide entonces toda estructuralidad fija dada al aparecer: la torna, más bien in-constante, intermitente, fantasmática incluso. Aparecer inconstante o digestión interrumpida por el vómito, asimilación frustrada que transforma la identidad misma del que come. Comer-alotro, comer-con-otro y ser comido-por-otro son las formas de una dietética que hace del sí mismo ya otro y que, a partir de allí, lo llama constitutivamente a la responsabilidad y a la hospitalidad. Una economía de la violencia, economía doméstica, de la cocina ciertamente, que es una ley de lo propio como ley de la violencia, cuya consiga en la de un il faut, dice Derrida, de un "es preciso" que no es sino el de un "buen comer" y, por sobre todo, el de ser, a la vez, transformado.

\section{Financiamiento}

Este trabajo fue realizado en el marco del proyecto FONDECYT No 11180180. 


\section{Referencias bibliográficas}

Aristóteles. "Tópicos”. En Organon I. Miguel Candel Sanmartín traductor. Madrid: Editorial Gredos, 1982.

. “Analíticos posteriores”. En Organon II. Miguel Candel Sanmartín traductor. Madrid: Editorial Gredos, 1995.

. Ética nicómacomáquea. Emilio Lledó traductor. Madrid: Editorial Gredos, 1995.

. Acerca del alma. Tomás Calvo Martínez traductor. Madrid: Editorial Gredos, 2014.

Benjamin, Walter. Tesis de filosofia de la historia. Jesús Aguirre traductor. Madrid: Editorial Taurus, 1973.

. "Para una crítica de la violencia", Pablo Oyarzún traductor. En Letal e incruenta. Walter Benjamin y la crítica de la violencia, Pablo Oyarzún, Federico Rodríguez y Carlos Pérez L. eds. Santiago: Lom ediciones, 2017.

Campos, Valeria. Violencia y fenomenología. Derrida entre Husserl y Levinas. Santiago: Ediciones Metales Pesados, 2017.

. Transacciones peligrosas. Economías de la violencia en Jacques Derrida. Santiago: Pólvora ediciones, 2018.

. "The Original Polemos. Phenomenology and Violence in Jacques Derrida". En The Meanings of Violence. From Critical Theory to Biopolitics, Gavin Rae y Emma Ingala. eds. Nueva York: Routledge, 2018.

. "Asesinar al otro. Ética, violencia y poder en la filosofía de Emmanuel Lévinas". Hybris Revista de Filosofía 10, no. 1 (2019): 95-120.

Derrida, Jacques. Introduction a L'origine de la géometrie de Husserl. París: PUF, 1962. . "Violence et métaphysique. Essai sur la pensée d'Emmanuel Levinas". En La ecriture et la différence. París: Galilée, 1967.

. De la grammatologie. París: Galilée, 1967. . La dissémination. París: Seuil, 1972. . Marges de la philosophie. París: Minuit, 1972. . Glas. París: Galilée, 1974. 
. "Economimesis". En Mímesis, des articulations, Sylviane Agacinski, Sarah Kofman y Jacques Derrida editores. París: Aubier, 1975.

. "Fors". En Cryptonymie: le verbier de l'homme aux loups, Nicolas Abraham, Maria

Torok y Jacques Derrida. París: Flammarion, 1976.

. Mémoires, pour Paul de Man. París: Galilée, 1988.

. Manger l'autre: politiques de l'amitié. Seminario inédito archivado en la Derrida

Collection /Critical Theory Collection/ Special Collections and Archives/ UCI Library,

California, Estados Unidos. Caja 10, archivos 8-15. 1989-1990.

- Rhétoriques du cannibalisme. Seminario inédito archivado en la Derrida

Collection /Critical Theory Collection/ Special Collections and Archives/ UCI Library,

California, Estados Unidos. Caja 20, archivos 13-15. 1990-1991.

. Le problème de genèse dans la philosophie de Husserl. París: PUF, 1990.

. Donner le temps. La fausse monaïe. París: Galilée, 1991.

. "Prénom de Benjamin". En Force de loi. Le "fondament mystiquet" de l'autorité.

París: Galilée, 1994.

. Hostipitalité. Seminario inédito archivado en la Derrida Collection/Critical

Theory Collection/ Special Collections and Archives/ UCI Library, California, Estados

Unidos. 1995-1996.

. "Mot d'accueille". En Adieu à Emmanuel Lévinas. París: Galilé, 1997.

. Voyous. París: Galilée, 2003.

. Kant, el judio, el alemán. Patricio Peñalver traductor. Madrid: Trotta, 2004.

. "Hay que comer bien. El cálculo del sujeto". Confines 17 (2005). Traducción de

Virginia Gallo y Noelia Billi.

. La voix et le phénomène. París: PUF-Quadrige, 2006.

. Spectres de Marx. L'État de la dette, le travail du deuil et la nouvelle Internationale.

París: Galilée, 1993.

. Heidegger: la question de l'Être et l'Histoire. Cours de L'ENS-Ulm 1964-1965.

París: Galilée, 2013.

. "Geschlecht I. Diferencia sexual, diferencia ontológica". En Psyché Invenciones

del otro, Alejandro Madrid traductor. Buenos Aires: La Cebra editores, 2017.

Krell, David Farrell. "All You Can't Eat: Derrida's Course, "Rhétorique Du Cannibalisme" 
(1990-1991). Research in Phenomenology 3 (2006): 130-180.

Heidegger, Martin. Ser y tiempo. Jorge Eduardo Rivera traductor. Santiago: Editorial Universitaria, 1997.

Johnson, Cristopher. System and Writing in the Philosophy of Jacques Derrida. Cambridge: Cambridge University Press, 1993.

Levinas, Emmanuel. Totalité et infini. Essai sur l'extériorité. Dordrecht: Kluwer Academic Publishers, 1988.

De otro modo que ser o más allá de la esencia. Antonio Pintor Ramos traductor. Salamanca: Editorial Sígueme, 1987.

Malabou, Catherine. "Économie de la violence, violence de l'économie. Derrida et Marx". Reveu philosophique de la France et de l'Étranger 2 (1990): 303-24.

Métraux, Alfred. Antropofagia y cultura. Silvio Mattoni traductor. Buenos Aires: El Cuenco de Plata editores, 2011.

Peñalver, Patricio. Argumento de alteridad. Madrid: Editorial Caparrós, 2000.

Rodríguez, Federico. "Centaurus. Para una ontología poética de la violencia". En Letal e incruenta. Walter Benjamin y la crítica de la violencia, Pablo Oyarzún, Federico Rodríguez y Carlos Pérez L. eds. Santiago: Lom ediciones, 2017.

Vivieros de Catro, Eduardo. "Lévi-Strauss nos 90 a antropologia de cabeça para baixo". Mana 4, no. 2 (1998): 119-26.

. "O mármore e a murta: sobre a inconstância da alma selvagem". En A inconstância da alma selvagem e outros ensaios de antropología, 183-264. Sao Paulo: Cosac Naify, 2002.

Vieillard-Baron, Jean-Louis. "La 'Wirklichkeit' ou réalité effective dans les 'Principes de la philosophie du droit' de Hegel”. Revue Philosophique de Louvain 103, no. 3 (2005): 347-63.

Recibido:

Aceptado:

\section{Sobre la autora}


Valeria Campos Salvaterra. Docente e investigadora del Instituto de Filosofía de la Pontificia Universidad Católica de Valparaíso (Valparaíso, Chile). Doctora en filosofía por la Pontificia Universidad Católica de Chile. Es autora de los libros Violencia y fenomenología. Derrida entre Husserl y Levinas (Santiago: Editorial Metales Pesados, 2017), Transacciones peligrosas. Economías de la violencia en Jacques Derrida (Santiago: Pólvora editorial, 2018), Comenzar por el terror. Ensayos sobre filosofía y violencia (Santiago: Editorial Prometeo, 2019), así como de numerosos artículos sobre el problema de la violencia en su relación con el discurso en la filosofía contemporánea. Actualmente, ha ampliado su campo de estudio hacia el uso de figuras retóricas asociadas a la alimentación en la filosofía. Asimismo, realiza investigaciones de filosofía aplicada sobre alimentación, con énfasis en estudios culturales y políticos. Correo electrónico: campos.valeria@gmail.com. 